\title{
Ensino de Geografia como um campo de pesquisa no Brasil: uma história da disciplina acadêmica no contexto das narrativas de Lívia de Oliveira
}

\author{
Geórgia Stefânia Picelli Laubstein-Oliveira \\ Programa de Pós-Graduação da Universidade Estadual Paulista, campus de Rio Claro, São Paulo -Brasil \\ georgia_picelli@yahoo.com.br \\ João Pedro Pezzato \\ Departamento de Educação da Universidade Estadual Paulista, campus de Rio Claro, São Paulo -Brasil \\ jpezzato@rc.unesp.br
}

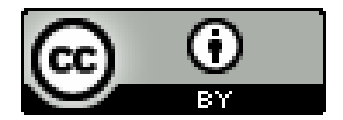

EDUCAÇÃO: Teoria e Prática, Rio Claro, SP, Brasil - eISSN: 1981-8106

Está licenciada sob Licença Creative Common

\section{Resumo}

O presente texto registra as memórias da professora Lívia de Oliveira com o objetivo de contribuir para a escrita da história da Geografia como disciplina acadêmica. A trajetória da professora possibilita compreendermos o contexto histórico de construção das universidades públicas do Estado de São Paulo, Brasil. Nascida no interior do Estado de São Paulo, em 1927, Lívia atuou no ensino básico e no superior. Foi também pioneira no desenvolvimento da investigação acadêmica para a área do ensino de Geografia, em especial no campo da cartografia escolar. Seu trabalho possibilitou que a cartografia escolar deixasse de ser uma simples transposição de conceitos e métodos técnicos para o ensino básico.

Palavras-chave: Ensino de Geografia. Memórias. Educação. História das Disciplinas. História da Universidade Pública.

\section{Teaching Geography as a field of research in Brazil: a history of academic discipline in the context of Livia de Oliveira's narratives}

\begin{abstract}
This text records the memories of teacher Lívia de Oliveira aiming to contribute to the writing of the history of geography as an academic discipline. The trajectory of the teacher allows us to understand the historical context of the construction of public universities in the state of São Paulo, Brazil. Born in the state of São Paulo in 1927, Lívia worked in elementary school and also with higher education. She was also a pioneer in the development of
\end{abstract}


academic research in the area of teaching geography, especially in the field of school cartography. Her work enabled the school cartography stop being a simple transposition of concepts and technical methods into the elementary school.

Keywords: Teaching Geography. Memories. Education. History of Disciplines. History of Public University.

\section{Enseñanza de Geografía como un campo de investigación en Brasil: una historia de la disciplina académica en el contexto de las narrativas de Lívia de Oliveira}

\section{Resumen}

El presente texto registra las memorias de la profesora Lívia de Oliveira con el objetivo de contribuir para la escritura de la historia de la Geografía como disciplina académica. La trayectoria de la profesora posibilita comprender el contexto histórico de la construcción de las universidades públicas del Estado de São Paulo, Brasil. Nacida en el interior del Estado de São Paulo, en 1927, Lívia actuó en la enseñanza básica y en la superior. Fue también pionera en el desarrollo de la investigación académica para el área de la enseñanza de Geografía, en especial en el campo de cartografía escolar. Su trabajo posibilitó que la cartografía escolar dejara de ser una simple transposición de conceptos y métodos técnicos para la enseñanza básica.

Palabras clave: Enseñanza de Geografía. Memorias. Educación. Historia de las Disciplinas. Historia de la Universidad Pública. Cartografía Escolar.

\section{Introdução}

Este artigo tem como principal objetivo discutir a trajetória profissional de Lívia de Oliveira, registrada nos depoimentos a respeito de seu percurso como professora e pesquisadora do Ensino de Geografia. A análise de sua trajetória profissional pode contribuir para a pesquisa no campo do Ensino de Geografia.

Foi na década de 1930 que a Geografia surgiu como curso superior universitário e, assim, recebeu certo reconhecimento como um campo de conhecimento válido no Brasil. Entretanto, como conhecimento escolar que integra o conjunto de disciplinas do currículo oficial, a Geografia já era ensinada nas escolas secundárias antes de haver formação profissional específica. Nesse período, a disciplina escolar era ministrada por intelectuais da comunidade, advogados, engenheiros e professores leigos.

Entre as décadas de 1960 a 1980, a Geografia brasileira passou por inúmeras transformações, que influenciaram não somente a Geografia enquanto conhecimento acadêmico, mas também seu ensino nas salas de aulas da escola básica. Tais mudanças 
foram decorrentes das publicações destinadas ao ensino, em grande parte compostas por livros didáticos, e de determinações de políticas públicas que incidiam na dimensão curricular do ensino no período.

A professora Lívia de Oliveira iniciou sua carreira docente universitária na década de 1960, e desenvolveu, no final da década de 1970 e início da década de 1980, importantes pesquisas sobre a Cartografia para a escola básica. Suas pesquisas tiveram como referencial teórico as contribuições de Jean Piaget, e tais concepções não estavam presentes nas discussões relativas ao ensino de Geografia no país. A professora Lívia foi, assim, a precursora no desenvolvimento das pesquisas da Cartografia Escolar e do Ensino de Geografia. Seu trabalho possibilitou que o ensino de Geografia passasse a ser visto como um tema de pesquisas acadêmicas, no âmbito da Ciência Geográfica. Lívia de Oliveira praticamente inaugurou um campo de pesquisa no Brasil, essa foi uma de suas principais contribuições.

\section{Depoimentos de memória e a história da Geografia acadêmica: o registro de uma trajetória}

$\mathrm{Na}$ perspectiva da pesquisa qualitativa, selecionamos a História Oral que, ao estabelecer procedimentos de trabalho com entrevistas e transcrição de depoimentos, possui técnicas específicas, bem como um conjunto de conceitos e procedimentos metodológicos, para a investigação que se propõe a eleger a oralidade como fonte principal de estudo (AMADO; FERREIRA; 2001, p. xvi).

O relato oral da professora Lívia é o ponto de partida para as discussões realizadas ao longo deste trabalho. Sua narrativa é concebida como um documento construído, assim como a produção bibliográfica da professora Lívia, os demais documentos que tratam da temática estudada e esta própria pesquisa. Tais produções são documentos-monumentos (BOURDIEU, 2008), isto é, construções resultantes de uma montagem, compostos por materiais da memória, que são os monumentos, ou herança do passado e que guardam a história de uma época, da sociedade que os produziu. 
Segundo Jacques Le Goff (1990, p.535-548), "o monumento é um sinal do passado. Atendendo às suas origens filológicas, o monumento é tudo aquilo que pode evocar o passado, perpetuar a recordação, por exemplo, os atos inscritos".

No decorrer da produção de registros, interpretamos as histórias contadas pela professora Lívia, considerando que seu relato biográfico é composto por fragmentos, trechos de uma trajetória.

Assim sendo, não pretendemos registrar a história de vida de uma pessoa, uma vez que tratar a vida de uma pessoa como uma história "[...] talvez seja conformar-se com uma ilusão retórica, uma representação comum da existência que toda uma tradição literária não deixou e não deixa de reforçar" (BOURDIEU, 2001, p.185).

Mesmo que uma pessoa queira revelar todas as suas verdades, encontrará obstáculos porque sua identidade, constituída socialmente, inscreve-a num tempo e espaço determinados. Aquele que resolve contar seu passado certamente irá se esforçar na apresentação oficial de si mesmo. Da mesma forma, a construção do discurso tende a ser influenciada pelas leis da biografia oficial, isto é, tende a ser uma montagem na qual o relato de vida se apresenta como oficial (BOURDIEU, 2001)

Nesse contexto, os depoimentos da Professora Lívia foram registrados e a partir deles foi possível traçar uma das vias percorridas pelo ensino de Geografia no Brasil. Ao estabelecermos conexões entre o relato oral, a análise da produção acadêmica e do estudo da bibliografia, conhecemos e compreendemos o espaço social em que nossa narradora está inserida.

As entrevistas realizadas primam por estabelecer uma aproximação necessária entre entrevistador e entrevistada. Para Bourdieu (2008, p.695), o distanciamento entre pesquisador e narrador (ou entrevistador e entrevistada) pode gerar uma "comunicação violenta"; esta ocorre quando a violência simbólica não pôde ser evitada ou mesmo reduzida durante a entrevista. Há, numa "comunicação violenta", uma dissimetria entre pesquisador e entrevistado; essa dissimetria é acentuada quando existem diferenças hierárquicas de capital, especialmente de capital cultural.

Isso posto, consideramos que as memórias sempre podem suscitar novos objetos, novos olhares e, por esse motivo, as entrevistas, transcritas e transformadas em uma 
narrativa, são sempre consultadas e relidas. Além disso, são documentos por proporcionar leituras diferentes, adequadas a diferentes problemas de pesquisa.

Dentre as diversas possibilidades de análise oferecidas pelos indícios observados nas entrevistas, optamos por trazer à tona uma discussão advinda da leitura de Ivor Goodson (1990). Esse autor discute o desenvolvimento das disciplinas acadêmicas e, como veremos adiante, suas reflexões podem contribuir para a compreensão dos caminhos trilhados pela investigação a respeito do ensino de Geografia no Brasil.

Como nossa fonte principal de análise é o relato oral da professora Lívia de Oliveira, nossa especial atenção recaiu nas reflexões que contemplam o espaço acadêmico vivido por nossa depoente enquanto estudante e professora universitária. Por esse motivo, detivemonos a discutir sua experiência como discente no curso de Geografia, realizado na Universidade de São Paulo (USP), e como docente na Faculdade de Filosofia, Ciências e Letras de Rio Claro (FFCL), atualmente UNESP.

\section{O Ensino de Geografia: um caminho para a definição de uma disciplina acadêmica}

Como apontado anteriormente, o objetivo deste trabalho foi o de compreender as estratégias da trajetória profissional da Professora Lívia no contexto do processo de configuração institucional da Geografia acadêmica na Universidade Estadual Paulista.

A constituição da Geografia como disciplina acadêmica no Brasil contou com a participação decisiva de grupos de intelectuais da USP e também da FFCL de Rio Claro. Nesse processo, a disciplina passa a se constituir como um saber autônomo nas instituições que congregam as universidades.

Ao se separar da História, na Universidade de São Paulo (USP), a partir de 1956, a Geografia passou a ser reconhecida como um campo de saber autônomo, com objeto e métodos próprios. Na Faculdade de Filosofia da USP, essa separação representou a oportunidade de ascensão na carreira acadêmica para professores que já lecionavam como assistentes de Cátedras já estabelecidas.

Devido à própria estrutura das Cátedras, os alunos recém-formados ou professores que ainda não faziam parte do quadro docente da instituição dificilmente conseguiriam, no curso de Geografia da USP, alcançar um lugar na carreira universitária. 
Assim, vislumbrando a possibilidade de ascensão profissional na instituição, foram criados os Institutos Isolados e o curso de Geografia foi instalado. Nos Institutos Isolados de Ensino Superior - como era o caso da FFCL de Rio Claro - o sistema de Cátedras foi, em sua grande maioria, substituído pela estrutura de Departamentos; em alguns casos, a Cátedra era oferecida ao professor sem a necessidade de passar por todas as etapas de docência até conseguir ser catedrático. Essas estratégias permitiram a inserção de professores jovens, recém-formados e que ainda não haviam se especializado em uma área específica da Geografia.

No curso de Geografia e História da USP, havia cátedras mais ligadas à História e outras mais ligadas à Geografia. Com a separação da Geografia e da História, em 1956, houve a possibilidade de que cada uma dessas disciplinas se desenvolvesse de maneira mais autônoma, necessitando, portanto, de professores que pudessem contribuir com a especialização do conhecimento em cada uma dessas áreas, nessa nova configuração, como distintas entre si.

Entretanto, essa especialização não seria alcançada, necessariamente, através da contratação de novos docentes, mas, sim, a partir do aproveitamento dos professores que já lecionavam na instituição. Isso exigiu dos professores que já eram da casa o desenvolvimento de pesquisas em áreas determinadas, capazes de garantir a especialização do conhecimento na instituição. Nesse sentido, os financiamentos eram essenciais para garantir o desenvolvimento das investigações propostas.

O sistema de cátedras, adotado pela maioria das universidades brasileiras, permitia ao professor catedrático um cargo vitalício. Tal sistema foi adotado pela USP na Faculdade de Filosofia, Ciências e Letras e, posteriormente, por alguns Institutos Isolados espalhados pelo Estado de São Paulo. Segundo Roiz (2004, p.93), o aspecto legal da criação das cátedras

compreende desde a incorporação de um corpo de regras que operem o desdobramento do processo que regeria a forma de seleção do profissional até a caracterização de suas funções. A organização das cadeiras efetua a disposição curricular de cada curso e delibera a maneira como os profissionais deverão agir dentro de cada seção ou subseção na Faculdade de Filosofia, Ciências e Letras da Universidade de São Paulo. Por fim, os locais ou espaços de sociabilidade que se formava no interior de cada curso caracterizavam os laços de amizade, as escolhas políticas e as predisposições teóricas e práticas de cada um dos professores - na cadeira, que atuava profissionalmente, e no curso, entre 'os pares'.

Ao longo do tempo, as regras para concorrer a uma vaga como professor catedrático foram reestruturadas. Mas, segundo Roiz (2004), a carreira docente no início do 
funcionamento da Faculdade de Filosofia da USP não exigia o título de doutor, mesmo porque os cursos de pós-graduação, no Brasil, começaram a aparecer anos depois. De maneira geral,

[...] o início da carreira dependia mais de oportunidade, porque decorriam de assistências a professores efetivos. Era por meio desse 'estágio remunerado' (por assim dizer) que começava a carreira docente. Ao desempenhar as funções de assistente, anos depois renomeada como auxiliar de ensino, que o recém-formado aprendia a elaborar e planejar as aulas e o conteúdo das disciplinas, que observava como era o funcionamento administrativo da cadeira e que iniciava as primeiras pesquisas acadêmicas. Essas pesquisas que davam origem às teses de doutoramento dos assistentes (ou auxiliares de ensino). Ao defenderem seu doutoramento, uma outra etapa se iniciava. A carreira não tinha estabilidade, a menos que se fosse o titular da cadeira. Mesmo sem estabilidade plena, observouse que foram ínfimos os casos em que os recém-doutores que já atuavam na instituição como assistentes (ou como auxiliares) eram dispensados de suas funções docentes. Aos iniciantes, embora não tivessem estabilidade garantida legalmente, restava, ao concluírem o doutoramento, esperar a oportunidade de prestarem o concurso para professor catedrático. Nesse caso, a aproximação e confraternização com os 'pares' era fundamental para alicerçarem (além de rituais de consagração) os laços de amizade (ROIZ, 2004, p.98-99).

No que se refere à Geografia, o curso da USP em Geografia e História inicialmente contava com a cadeira de Geografia Física e Humana sob a regência do professor Pierre Monbeig. Essa cadeira foi desmembrada em Geografia Física e Geografia Humana, por meio de medida institucional.

No final da década de 1930, a cátedra de Geografia Física teve como assistente o professor João Dias da Silveira, que assumiu a cadeira como professor interino em 1938. Ele iniciou suas atividades na Geografia da USP em 1936, como assistente de ensino, encarregado de preparar e ministrar aulas no curso de Geografia Física e Humana sob a coordenação do professor Pierre Monbeig, o qual foi seu orientador na tese de doutorado, defendida em 1946. Em 1950, o professor João Dias da Silveira assumiu a cátedra de Geografia Física (ROIZ, 2004, p.115).

O surgimento de uma nova disciplina dentro da cátedra, ou disciplina base, permitia o desmembramento de uma cadeira, garantindo o trabalho docente no meio acadêmico, além de possibilitar discussões mais específicas em torno de um determinado tema.

Dessa forma, a especialização do conhecimento tornava possível a formação de uma área específica e, portanto, de uma disciplina verdadeiramente acadêmica. Enquanto a Geografia possuía apenas algumas cadeiras dentro do curso de Geografia e História, sua 
ampliação como uma área única de conhecimento ficou impossibilitada de acontecer, assim como a ampliação da carreira docente a outros candidatos a professores universitários.

Ao se desmembrar da História, em 1956, a Geografia conseguiu garantir seu lugar no âmbito acadêmico como uma disciplina universitária, principalmente por ter em sua estrutura disciplinas específicas que a caracterizam como uma Ciência de referência, com objeto e métodos próprios. No meio acadêmico, essa separação representou uma oportunidade de ascensão para professores recém-formados.

Em meados da década de 1950 e 1960, os financiamentos à Educação no Estado de São Paulo estavam atrelados à ideia de expansão da oferta do ensino técnico e na qualificação de mão de obra para o trabalho devido à expansão da industrialização verificada no Estado.

Nos Institutos Isolados, os financiamentos estavam mais propensos a acontecer, devido aos objetivos com que foram criados: instruir uma parcela da população muito importante para o desenvolvimento e expansão das atividades econômicas do Estado. Assim, o governo estadual, à época, deixava evidente que seu maior interesse estava em investir nos cursos dos Institutos Isolados.

Dessa forma, podemos dizer que o trabalho num Instituto Isolado significava, dentre outras coisas, maiores oportunidades de se obter financiamentos em pesquisas e infraestrutura, além de apresentar ocasião para a ascensão na carreira acadêmica.

E foi exatamente o que aconteceu com o Professor João Dias da Silveira: catedrático da USP na Cadeira de Geografia Física. O Professor aceitou o convite do Governador do Estado, em 1957, para ser o Diretor da FFCL de Rio Claro-SP.

Ao assumir a direção da FFCL de Rio Claro, o professor João Dias teve garantida sua ascensão na carreira acadêmica, além de possibilitar a ampliação de financiamentos em pesquisas nos cursos que compunham a instituição recém-criada.

Ao escrever para o Governador do Estado, o professor João Dias esclareceu que o aceite ao convite para ser diretor da FFCL estava atrelado a certas garantias, muitas delas relacionadas a investimentos em infraestrutura:

É natural que, coerentes com os pontos de vista mais do que uma vez expostos pela Congregação da Faculdade de que faço parte, pontos de vista aos quais sempre nos associamos, estivéssemos na obrigação de declinar da honrosa incumbência. Vossa excelência, entretanto, antes que nos manifestássemos, declarou que o convite era para dirigirmos a instalação de uma Faculdade de alto nível e em linhas renovadoras. Tendo Vossa Excelência colocado nesses termos a 
instalação do novo instituto, criava, evidentemente, situação nova para nós. Não podíamos, como não podemos, duvidar dos propósitos do Governo, "máxime" quando Vossa Excelência, na referida audiência, fez questão de reafirmar que, para atingir tais escopos, estão as autoridades dispostas a oferecer todo o amparo e colaboração necessárias. Tudo indicava ter o Governo de Vossa Excelência deliberado depois de atentar maduramente para o problema [...] (SILVEIRA, 1988, apud BUSCHINELLI, 1988, p.17).

Em seu discurso, podemos perceber uma preocupação em justificar o aceite ao convite para os colegas da USP e, por consequência, para todos que se opunham à política de instalação dos IIES.

Diante da necessidade de justificar a existência da FFCL de Rio Claro, e também da própria Geografia como uma disciplina válida dentro da Faculdade recém-criada, o professor João Dias procurou trazer para a instituição de Rio Claro um corpo docente disposto a desenvolver e fortalecer o arcabouço teórico e prático da Geografia. Para tanto, arregimentou professores de outras universidades brasileiras, tais como da própria USP, do Rio de Janeiro, de Santa Catarina, além de recém-formados que almejavam seguir a carreira universitária.

Na FFCL de Rio Claro, a estratégia utilizada para garantir a existência das carreiras acadêmicas e da própria Ciência Geográfica foi, de certa forma, torná-la necessária à sociedade. Importante salientar que havia um contexto histórico, social, político e econômico propício à instalação de cursos de formação de professores no interior do país. Os mecanismos que tornavam a Geografia um saber necessário à sociedade já estavam sendo articulados através das legislações que determinavam a estrutura dos currículos escolares, especialmente no que tange aos exames exigidos para a admissão nos níveis mais elevados de escolarização. Além disso, com a crescente urbanização e industrialização brasileira, verificada ao longo das décadas de 1940-1960, as legislações educacionais tenderam a privilegiar o ensino técnico, mais prático e útil à sociedade que buscava um lugar no mundo do trabalho.

Nesse contexto, encontrava-se a Geografia da USP numa situação perturbadora ao se separar da História. Por um lado, havia uma situação favorável, decorrente da oportunidade de desenvolver-se como um campo de conhecimento autônomo. Por outro, havia uma situação difícil porque precisava articular mecanismos que garantissem seu lugar e sua existência numa Faculdade já constituída e com uma estrutura em que as cátedras prevaleciam. 
A Geografia da USP precisava ser reconhecida como uma ciência num ambiente instável e, nesse sentido, tornava-se muito importante o desenvolvimento de estudos e pesquisas sobre os métodos da Geografia e seu objeto de estudo, bem como o aumento de recursos financeiros para as pesquisas.

Na USP, no início da década de 1960, houve uma tendência na especialização do conhecimento geográfico através das pesquisas realizadas na pós-graduação, além de uma busca crescente por recursos financeiros.

Em contrapartida, na FFCL de Rio Claro, a Geografia, desde o início, procurou se estruturar como uma área de conhecimento autônoma, isto é, como uma disciplina acadêmica, enquanto que na USP a Geografia lutava para manter o seu status como uma ciência de referência.

Na USP, as preocupações com a Ciência Geográfica, tais como a dicotomia entre Geografia Humana e Geografia Física, faziam parte da maioria das discussões acadêmicas, bem como dos trabalhos publicados em periódicos da época. Em contrapartida, discussões sobre a geografia ensinada nas escolas continuavam em segundo plano.

Mais uma vez, acentuou-se a separação entre Bacharelado e Licenciatura, na medida em que o Bacharelado se tornava o caminho necessário ao desenvolvimento de pesquisas que definiriam os parâmetros da Ciência Geográfica em discussão.

Além disso, como apontado anteriormente, a especialização do conhecimento geográfico na Universidade representou, dentre outras coisas, a ampliação das possibilidades de financiamentos tanto na USP quanto na FFCL de Rio Claro.

Cabe evidenciar que, para Goodson (1990, p.251), a intrínseca relação entre status acadêmico e a alocação de recursos explica as tentativas de uma disciplina para se tornar uma matéria acadêmica. Segundo ele:

Basicamente, uma vez que mais recursos são dados à matéria acadêmica que é objeto de exame, ensinada aos estudantes capazes, o conflito com respeito ao status do conhecimento examinável é, acima de tudo, uma batalha em torno dos recursos materiais e das perspectivas de carreira de cada professor da matéria ou da comunidade da matéria.

Assim, vemos que as diferenças entre as pesquisas realizadas na USP e na FFCL de Rio Claro, no período estudado, são fruto da separação entre Bacharelado e Licenciatura, que, por sua vez, aconteceu como uma estratégia necessária à definição de um modelo de Geografia nas duas instituições estudadas. As modificações verificadas no processo de 
definição do modelo de Geografia a ser seguido determinaram o teor das pesquisas na USP e na FFCL de Rio Claro; ambas se tornaram difusoras de pesquisas inéditas, essenciais à sobrevivência da Geografia enquanto ciência, porém, diferentes quanto aos métodos utilizados e ao foco das investigações.

Dessa forma, compreendemos que o contexto histórico proporcionou a viabilidade da FFCL de Rio Claro. O processo de profissionalização da carreira docente em curso, tanto no nível do ensino superior quanto no ensino básico do período, contribuiu para que o curso de Geografia fosse justificado socialmente em uma instituição pública.

A trajetória que levou a Geografia brasileira a ser reconhecida como uma disciplina acadêmica contou com caminhos diferentes, preconizados por duas instituições importantes como a USP e a Faculdade de Filosofia, Ciências e Letras de Rio Claro. Embora esses caminhos tenham sido diferentes, os objetivos almejados eram os mesmos: fortalecer o conhecimento geográfico, garantir o espaço conquistado pela Geografia no âmbito acadêmico e também as carreiras docentes.

Entretanto, foi justamente esse caminhar diverso que possibilitou à Geografia brasileira se desenvolver de forma ampla, contemplando, ao longo do tempo, pesquisas sobre os mais variados temas, inclusive sobre o Ensino de Geografia.

Se as discussões na USP, ao menos até a década de 1960, foram vitais para o fortalecimento do corpo teórico e metodológico da Geografia, a FFCL de Rio Claro, através da atuação da professora Lívia, trouxe à tona preocupações e reflexões a respeito do ensino de Geografia. O destaque para o desenvolvimento de pesquisas com temáticas relativas ao ensino ficou principalmente a cargo da Professora Lívia, na instituição de Rio Claro, que veio a contribuir para o desenvolvimento de uma linha de investigações especifica a respeito do ensino de Geografia ou, como a própria depoente denomina, a Didática da Geografia.

A narrativa elaborada a partir dos relatos da professora Lívia traz à tona diversas pistas sobre como o ensino de Geografia foi se tornando uma área de pesquisa no Brasil. Conhecer e entender os caminhos percorridos pela Geografia enquanto produção acadêmica Ciência é fundamental, especialmente quando as reflexões sobre este percurso oferecem relevantes considerações a respeito da constituição de uma área de pesquisas até então não consolidada: o Ensino de Geografia. 
O contato com as ideias de Ivor Goodson (1990), especialmente no que se refere à história das disciplinas acadêmicas e sua institucionalização nas Universidades, concomitante à análise das entrevistas realizadas com a professora Lívia, contribuiu para uma história da institucionalização da Geografia na Universidade Brasileira. Mais particularmente, o estudo permitiu que fossem registrados os mecanismos engendrados no interior do meio universitário em que a Geografia foi se estruturando como uma Ciência de referência com seus desdobramentos temáticos no campo da pesquisa.

Ao rememorar sua graduação na USP, Lívia nos obrigou a mergulhar no universo acadêmico da Geografia frequentada por ela, fazendo-nos compreender que a Geografia daquele tempo - década de 1950 - ainda ligada diretamente à História, lutava para ser reconhecida como um campo de conhecimento válido dentro da própria Universidade. Somente no final da década de 1950, entre 1956 e 1957, é que a Geografia se estruturou como uma disciplina na Universidade, fazendo com que a Geografia da sala de aula fosse fortalecida como uma matéria escolar significativa para constar do currículo oficial.

Ao analisar a constituição da disciplina na Grã-Bretanha, Goodson (2001, p.156) aponta que a existência de exames nas escolas é condição necessária para a aceitação de uma disciplina acadêmica. Isso porque, de acordo com Chervel (1990) e Rodríguez Lestegás (2002), para que uma disciplina se constitua como tal são necessários 4 quesitos: a) uma vulgata (seleção de conteúdos, bibliografia, livros didáticos, prescrição curricular); b) uma série de exercícios (questionários, interpretação de texto etc.); c) procedimentos de motivação (questionamentos, problematizações, desafios etc.); e d) um conjunto de práticas de avaliação (exercícios de múltipla escolha, dissertação, questionários etc.).

No que se refere ao cumprimento de determinadas etapas de constituição das disciplinas escolares, a história da Geografia no Brasil não foi, em aspectos gerais, diferente da ocorrida na Grã-Bretanha, como demonstra o trabalho de Goodson (1990, 2008).

O trecho abaixo, transcrito a partir da entrevista de Lívia, evidencia que a Geografia já possuía, no Brasil, um status importante no currículo escolar nas décadas de 1950 e 1960, entretanto, ainda buscava sua afirmação enquanto ciência dentro da própria Universidade: 
Letras, eu fiz Enfermagem! Com 17 anos entrei na Enfermagem da USP; era apaixonada, como tudo que faço! Trabalhei, estudei, fui aos Estados Unidos, fiz o curso de especialização em Saúde Pública; trabalhava e dava minha aula, mas como eu era muito jovem não fui capaz de lidar com as coisas que aparecem na vida, e que depois apareceram na Geografia, mas aí fui capaz de lidar! Briguei feio na Faculdade de Higiene e eu saí; já estava fazendo Geografia quando fui trabalhar no Hospital de Ortopedia. Só depois é que eu fiz o Concurso para o magistério. (...) Aí eu fui lá (...)- naquela época era na Maria Antonia - vi o programa e decidi fazer o curso de História e Geografia por causa da História. Fiz um cursinho que era dado pelos próprios alunos da Filosofia. Na época a gente fazia o vestibular na própria Filosofia, não tinha essa história de coisa grande, nada! Só que naquela época não entrava Matemática; eu fiz Português, uma língua (Inglês), Geografia e História. Aí no vestibular - eu preciso contar para vocês!- eu entrei em primeiro lugar, aliás, a nota mais alta do vestibular do ano, de toda a Filosofia foi a minha nota (...) Todas as minhas notas foram assim, acima de 9! (...) Por isso a sorte foi essa, tudo o que caiu eu sabia, eu tinha vivido o que eu falava. Entrei na USP, na Geografia, era Geografia e História (Trecho de entrevista realizada com a professora Lívia de Oliveira, Rio Claro-SP, 2005).

Ao obter garantias de disciplina universitária, a Geografia conseguiria, também, preservar as carreiras docentes envolvidas. Esse processo continuou ocorrendo na década de 1960, época em que a professora Lívia iniciou sua atuação docente na universidade recentemente criada no interior de São Paulo, hoje denominada Universidade Estadual Júlio de Mesquita Filho (UNESP). Lívia de Oliveira, recém-formada, tinha como experiência de trabalho, no período em que tomou posse no cargo de docente do ensino superior, o magistério no ensino básico público. No âmbito do ensino superior, a docência na área do Ensino de Geografia teve início em 1962, assim como atesta sua narrativa:

Eu fui convidada pelo Doutor João para vir para Rio Claro. Naquela época, era o catedrático que convidava, e Doutor João me convidou para eu vir para cá bem antes do Doutorado! (...) Nessa época eu já tinha terminado a Geografia, já dava aula, já estava fazendo essas disciplinas, e o Doutor João sabia que eu tinha interesse de fazer carreira universitária. Aí depois, quando ele soube que mamãe havia morrido em 1961, ele voltou a me convidar. Aí eu disse que aceitava, por isso eu vim para Rio Claro em 1962. Ele foi meu professor e do meu concurso, também fizemos excursões juntos; conhecia o Doutor João desde o primeiro ano que eu fiz Geografia. (...) Só que eu tinha a minha cadeira no secundário; eu falei para ele que eu pediria um afastamento, mas que eu não iria largar, porque eu não sabia se ficaria aqui ou não. Demorou para sair meu afastamento, e eu vim pra cá em maio, e não em março. Ele queria que eu desse a disciplina que se chamava "Didática Especial de Geografia" para o quarto ano; (...) para os formandos aqui de Rio Claro. Ele me chamou bem atenção, porque ele não queria que eu transformasse a minha vinda como trampolim para eu passar para a Geografia; ele não queria que eu 
viesse pra cá e depois passasse a trabalhar em Geomorfologia - que eu gostava muito - em Climatologia, Urbana... Ele queria que eu viesse para trabalhar em Didática da Geografia; que eu fizesse pesquisa, ele usou bem a palavra, que eu iniciasse trabalhos de pesquisa em Ensino da Geografia, não em Geomorfologia. (...) Ele queria que eu fizesse pesquisa em Ensino de Geografia! Nem a USP tinha esse tipo de trabalho! Então o meu trabalho foi pioneiro, de vanguarda por causa da visão do Doutor João, porque foi ele que me colocou nisso. Quando eu cheguei não havia programa nem nada, havia a minha experiência de secundário e de primário (Trecho da entrevista realizada com a professora Lívia de Oliveira, Rio Claro-SP, 2005).

As exigências feitas pelo professor João Dias à Lívia de Oliveira, quanto ao teor de suas investigações - o Ensino da Geografia -, inauguraram uma linha de pesquisa necessária à busca pela manutenção do status adquirido pela Geografia, que, por sua vez, precisava ser também garantido no curso recém-criado da FFCL de Rio Claro.

Entre 1960 e 1970, surgiram algumas pesquisas com temáticas relativas ao ensino de Geografia. Vivia-se um contexto em que tais temáticas tinham um caráter de comprometimento social com o ensino. Foi naquele período que ocorreu a ampliação de vagas para a educação básica, em especial para os primeiros anos de escolarização. Exatamente no momento da institucionalização dos Estudos Sociais no currículo oficial.

No âmbito das políticas públicas para o ensino básico, a substituição da Geografia e da História pela disciplina denominada de Estudos Sociais, ocorrida no currículo da escola básica brasileira na década de 1970, ameaçou o status adquirido pela Geografia enquanto uma disciplina acadêmica; como consequência, as carreiras docentes dos cursos de Geografia também corriam sério risco.

Nesse contexto, as pesquisas sobre o Ensino de Geografia começaram a se tornar necessárias porque justificavam a necessidade do conhecimento geográfico na escola e, ao mesmo tempo, garantiam as carreiras docentes no meio acadêmico. A Geografia como disciplina acadêmica precisava se fortalecer, pois seu fortalecimento, dentro do meio acadêmico, garantiria a sobrevivência da Geografia no currículo escolar. E foi com o intuito de estabelecer um rigor metodológico para as investigações em andamento nos cursos de Geografia que as pesquisas sobre a Geografia começaram a definir um modelo teórico e metodológico a ser utilizado. Diversos temas começaram a ser investigados, dentre eles o Ensino de Geografia. 
Os trabalhos da professora Lívia inauguraram um campo de investigação na Geografia até então relegado à Pedagogia: as pesquisas sobre o Ensino de Geografia nas escolas básicas. Até o início da década de 1970, no Brasil, os estudos sobre o ensino da Geografia nas escolas eram realizados por pesquisadores ligados diretamente à Pedagogia e não pelos próprios geógrafos, formados nas Universidades brasileiras. Em geral, a sala de aula da escola básica não era preocupação dos geógrafos; a didática era uma disciplina própria do curso de Pedagogia e não da Geografia.

Entretanto, já na década de 1960, a professora Lívia iniciou reflexões sobre a Geografia da sala de aula e, mais tarde, na década de 1970, elaborou uma pesquisa que tentava estabelecer uma metodologia para o trabalho com mapas nas escolas. O caráter inovador de sua pesquisa consiste, principalmente, na introdução das concepções de Jean Piaget para o ensino de Geografia. Suas investigações, datadas das décadas de 1960 e 1970, estão inseridas no contexto em que a Geografia acadêmica precisava fortalecer seu status como uma disciplina acadêmica.

As dificuldades para a concretização de seu projeto profissional acabaram obrigando$a$ a entrar em contato com o universo da prática docente logo cedo, enquanto ain da cursava a licenciatura. Geralmente, essa prática acontece após o término da Faculdade; no caso de Lívia, o contato com o magistério como profissão ocorreu antes mesmo de se formar como professora de Geografia. Desde o início, Lívia teve a oportunidade de trabalhar os conhecimentos adquiridos no curso de Licenciatura:

Quando eu dava aulas lá em Pedro de Toledo eu tive muita sorte porque eu era nova, dava aula de Geografia, fazendo Filosofia. Então, entre os alunos eu tinha muita autoridade porque eu estava estudando e ensinava uma Geografia já moderna para eles. Nós fazíamos trabalhos, [...] tinha um riozinho lá e nós íamos dar aula no rio. Todas aquelas nomenclaturas de rio eram dadas dentro do rio. Depois nós íamos para Peruíbe ensinar a parte de mar; [...] estudávamos a cidade de Pedro de Toledo, e eles confeccionavam mapas (Trecho da entrevista realizada com a professora Lívia de Oliveira, Rio Claro-SP, 2005).

Vemos que sua prática docente estava imbuída de saberes e métodos da Geografia da época e, é significativo observar que, esses saberes não estavam diretamente relacionados à didática da Geografia do ensino básico. Eram conhecimentos mais 
relacionados à ciência de referência, tais como, temas da geomorfologia, climatologia etc. Daí sua prática, enquanto docente do ensino básico, priorizar as excursões, ou trabalhos de campo, práticas, aliás, difundidas no âmbito acadêmico da Geografia da Universidade de São Paulo e na unidade do campus de Rio Claro - SP.

As investigações sobre o ensino de Geografia surgiram, então, como uma consequência da atuação docente de Lívia de Oliveira na universidade, mais especificamente na Faculdade de Filosofia, Ciências e Letras de Rio Claro. De modo mais amplo, dizemos que o modelo institucional da recém-criada Faculdade onde Lívia foi convidada a atuar está associado aos projetos pessoais do Diretor da instituição e à necessidade particular de Lívia em garantir seu espaço profissional do ensino superior. A confluência de projetos profissionais com a história particular de constituição das instituições de pesquisa e ensino superior no Estado de São Paulo, Brasil, contribuiu para a consolidação da Geografia como disciplina autônoma no meio acadêmico. Esse fato pode ser um dos responsáveis pela permanência da disciplina no currículo de praticamente todas as séries do ensino básico no país. Tal fato não foi garantido em todos os países ocidentais, na atualidade.

Ao chegar à FFCL de Rio Claro para lecionar no curso de Geografia, Lívia se deparou com um modelo no qual a Didática fazia parte da grade curricular de praticamente todos os cursos, diferentemente da estrutura curricular dos cursos da Universidade de São Paulo. (BUSCHINELLI, 1988).

Ele queria que eu desse a disciplina que se chamava "Didática Especial de Geografia" para o quarto ano [...] Ele me chamou bem atenção, (...)Ele queria que eu viesse para trabalhar em Didática da Geografia; que eu fizesse pesquisa, ele usou bem a palavra, que eu iniciasse trabalhos de pesquisa em Ensino da Geografia, [...] Nem a USP tinha esse tipo de trabalho! [...] Quando comecei a trabalhar na Didática, senti que a questão do mapa é que seria importante para desenvolver trabalhos (Trecho da entrevista realizada com a professora Lívia de Oliveira, Rio Claro-SP, 2005).

Os trabalhos com mapas a que Lívia se refere dizem respeito às suas investigações sobre a aprendizagem do mapa em Geografia, baseadas nas concepções de Jean Piaget, um tema novo para a Geografia e também no campo educacional. 
Poucas eram as pesquisas em Educação que utilizavam referenciais de Piaget, e na Geografia nada ainda havia sido publicado sobre essa temática, tampouco pesquisas sobre o ensino de Geografia. Mas a professora Lívia, ainda na década de 1970, inaugurou na Geografia as reflexões sobre o ensino da cartografia nas escolas, embasada nas concepções piagetianas sobre representação do espaço na criança.

Portanto, o tema de sua investigação não surgiu de modo intuitivo, mas, sim, articulado à necessidade de se realizar pesquisas numa Faculdade, garantindo, assim, o status de excelência da instituição; estava articulado a todo um contexto favorável. A manutenção do status da recém-criada FFCL significava também, para a professora Lívia, a conquista de seu espaço, como mulher (docente e pesquisadora), no universo acadêmico e contribuiu para a constituição da Geografia como uma disciplina de alto status na Universidade.

\section{Considerações finais: uma longa trajetória de consolidação das pesquisas que tratam do Ensino de Geografia}

Ao longo das décadas de 1960 e 1970, as pesquisas sobre o Ensino de Geografia se tornaram essenciais à sobrevivência do Curso de Geografia da Universidade em que Lívia iniciou sua atuação docente e também à manutenção de sua própria carreira como professora universitária.

À época, a preocupação era desenvolver, no âmbito do ensino de Geografia, um arcabouço teórico e metodológico capaz de caracterizar e justificar as pesquisas que vinham sendo realizadas por docentes responsáveis por disciplinas ligadas ao Ensino de Geografia.

A análise de diferentes fontes de informações, como depoimentos, bibliografia, publicações oficiais e demais documentos, mostra-nos que a professora Lívia de Oliveira teve um papel extremamente importante na definição da Geografia como uma disciplina acadêmica no país. O Ensino de Geografia se tornou um caminho, uma estratégia para garantir sua carreira docente no âmbito acadêmico e trouxe, com seu trabalho, uma metodologia e um arcabouço teórico novos para a Geografia brasileira. 
A institucionalização do Ensino de Geografia como um campo de investigações surgiu, portanto, como uma consequência das estratégias engendradas no interior do meio acadêmico para sustentar o status da Geografia como uma disciplina necessária à universidade e à profissionalização dos docentes do ensino superior.

Sua trajetória de trabalho com o Ensino de Geografia apresenta uma variedade de contribuições. No âmbito do ensino e da pesquisa, Lívia veio e vem, ao longo de sua longa trajetória, introduzindo metodologias e técnicas de análise novas no campo da Geografia acadêmica brasileira, especialmente no âmbito da Cartografia escolar.

Portanto, conhecer os caminhos trilhados pelos profissionais envolvidos com o Ensino de Geografia pode nos ajudar a compreender não somente o passado, mas as estratégias adotadas para o ensino de Geografia nas escolas de educação básica e de ensino superior da atualidade.

\section{Referências}

AMADO, J.; FERREIRA, M. M. Apresentação. In: (Orgs.). Usos e Abusos da História Oral. Rio de Janeiro: Ed. FGV, 2001. p. xvi.

BOURDIEU, P. A Miséria do Mundo. Rio de Janeiro: Vozes, 2008.

BOURDIEU, P. A llusão Biográfica. In: AMADO, J.; FERREIRA, M. M. (Orgs.) Usos e Abusos da História Oral. Rio de Janeiro: Ed. FGV, 2001. p.183-191.

BUSCHINELLI, A. Subsídios para a História do Ensino Superior Oficial em Rio Claro: da Faculdade de Filosofia, Ciências e Letras ao Campus da Universidade Estadual Paulista "Júlio de Mesquita Filho" - UNESP. Rio Claro: Instituto de Biociências, 1988. Mimeo.

CHERVEL, A. História das Disciplinas Escolares: reflexões sobre um Campo de Pesquisa. Revista Teoria e Educação, Porto Alegre, v. 2, n.2, p.177- 229, 1990.

GOODSON, I. As Políticas de Currículo e de Escolarização. Petrópolis: Vozes, 2008.

GOODSON, I. O Currículo em Mudança: estudos na Construção Social do Currículo. Porto: Porto Editora, 2001.

GOODSON, I. Tornando-se uma Matéria Acadêmica: padrões de Explicação e Evolução. Teoria \& Educação, Porto Alegre, v. 2, n.2, p.230-254, 1990.

LE GOFF, J. História e Memória. Campinas: Editora da Unicamp, 1990. 
RODRÍGUEZ LESTEGÁS, F. Concebir la Geografía Escolar desde una Nueva Perspectiva: Una Disciplina al Servicio de la Cultura Escolar. Boletín de la A.G.E ., Madri, v. 3, n.33, p.173-186, 2002.

ROIZ, D. da S. A Institucionalização do Ensino Universitário de História na Faculdade de Filosofia, Ciências e Letras da Universidade de São Paulo, 1934-1956. 2004. 156 f. Dissertação (Mestrado em História) - Universidade Estadual Paulista. Franca, 2004.

Enviado em Junho/2012

Aprovado em Março/2014 